\title{
1q44 microdeletion syndrome
}

INSERM

\section{Source}

INSERM. (1999). Orphanet: an online rare disease and orphan drug data base. 1944 microdeletion syndrome. ORPHA:238769

1q44 microdeletion syndrome is a newly described syndrome associated with facial dysmorphism, developmental delay, in particular of expressive speech, seizures and hypotonia. 